\title{
NOTES
}

\section{High Performance Poly(1-oxotrimethylene) Fibers by Gel Spinning Method Using Aqueous Composite Metal Salt Solutions}

\author{
Toru MORITA, Ryu TANIGUCHI, and Jinichiro KATO ${ }^{\dagger}$ \\ Asahi Kasei Fibers Corporation, R\&D Laboratory For Fibers \& Textiles Technology, Nobeoka, Miyazaki 882-0031, Japan
}

(Received October 20, 2003; Accepted February 24, 2004; Published June 15, 2004)

KEY WORDS Poly(1-oxotrimethylene) / Fibers / Gel Spinning / Strength /

[DOI 10.1295/polymj.36.495]

Poly(1-oxotrimethylene) [Figure 1, abbreviated as "ECO"] obtained by alternating copolymerization of ethylene and carbon monoxide is attractive because of its high mechanical and thermal performance and utilization of inexpensive starting monomers. ECO is expected to form high strength and high elastic modulus fibers due to planar zigzag conformation and the smallest cross-sectional area in the crystalline phase $^{1}$ [ultimate tenacity $=266 \mathrm{cN} /$ dtex $(34.7 \mathrm{GPa})$; crystal elastic modulus $=2770 \mathrm{cN} / \mathrm{dtex}(361 \mathrm{GPa})]$.

Melt spinning of aliphatic polyketones such as ECO has been studied. ${ }^{2,3}$ However, the mechanical properties of the melt spinned fibers do not significantly differ from those of PET fibers widely used as industrial materials.

Wet spinning methods have been investigated for obtaining ECO fibers. Several organic solvents such as hexafluoroisopropanol and phenol ${ }^{4,5}$ have been used as solvents. Hot drawing of coagulated fibers produced high-performance polyketone fibers with high strength and high elastic modulus [tenacity $=$ $20 \mathrm{cN} /$ dtex $(2.6 \mathrm{GPa})$; elongation $=6.6 \%$; elastic modulus $=230 \mathrm{cN} /$ dtex $(30 \mathrm{GPa})]$. However, attempts at commercial production with these organic solvent systems have been abandoned because of toxicity, poor desolvation during spinning, and high cost of solvents. ${ }^{6}$

The authors ${ }^{7,8}$ studied aqueous solutions of various metal salts such as zinc chloride $\left(\mathrm{ZnCl}_{2}\right)$, calcium chloride $\left(\mathrm{CaCl}_{2}\right)$ and sodium chloride $(\mathrm{NaCl})$. Aqueous solutions have low toxicity, are inexpensive, and $\mathrm{ZnCl}_{2}$ aqueous solution has been industrially used as a solvent for polyacrylonitrile. Therefore, it seemed promising as an industrial solvent for ECO.

\section{EXPERIMENTAL}

\section{Materials \\ ECO was prepared according to Shell patents. ${ }^{9,10}$}

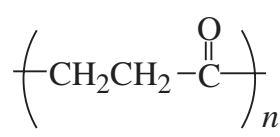

Figure 1. poly(1-oxotrimethylene) (ECO).

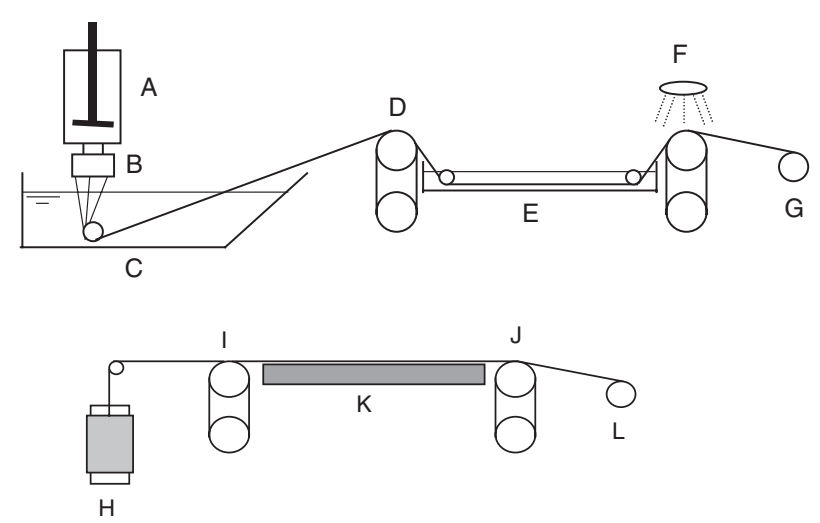

Figure 2. Schematic diagram of spinning apparatus.

Intrinsic viscosity $([\eta])$ of ECO measured in hexafluoroisopropanol at $25^{\circ} \mathrm{C}$ was $6.5 \mathrm{dL} / \mathrm{g}$.

\section{Phase Separation Temperature}

ECO solution was placed in a cylindrical glass bottle of 40-mm inner diameter. While controlling temperature by a thermostat, the temperature was gradually reduced from the dissolution temperature to $0^{\circ} \mathrm{C}$ at a rate of $10^{\circ} \mathrm{C}$ per hour. The phase separation temperature is defined as temperature at which the transparent solution becomes clouded.

\section{Spinning Method}

Using a plunger extruder (A), ECO solution was extruded at $80^{\circ} \mathrm{C}$ from a spinneret (B) with fifty 0.15 $\mathrm{mm}$ diameter holes through a $10-\mathrm{mm}$ air layer into a coagulation bath (C) at a spinning speed of $3 \mathrm{~m} /$ min. The coagulated fiber was picked up by a Nelson

${ }^{\dagger}$ To whom correspondence should be addressed (E-mail: Kato.jc@om.asahi-kasei.co.jp). 
Table I. ECO solubility and solution properties for aqueous metal salt solutions differing in composition

\begin{tabular}{ccc}
\hline No. & $\begin{array}{c}\text { Aqueous metal salt solution } \\
\text { composition } \\
\text { (wt } \%)\end{array}$ & $\begin{array}{c}\text { Phase separation } \\
\text { temperature } \\
\left({ }^{\circ} \mathrm{C}\right)\end{array}$ \\
\hline 1 & $\mathrm{ZnCl}_{2} / \mathrm{H}_{2} \mathrm{O}=75 / 25$ & Not observed \\
2 & $\mathrm{ZnCl}_{2} / \mathrm{NaCl} / \mathrm{H}_{2} \mathrm{O}=65 / 10 / 25$ & Not observed \\
3 & $\mathrm{ZnCl}_{2} / \mathrm{CaCl}_{2} / \mathrm{H}_{2} \mathrm{O}=65 / 10 / 25$ & Not observed \\
4 & $\mathrm{CaCl}_{2} / \mathrm{ZnCl}_{2} / \mathrm{H}_{2} \mathrm{O}=40 / 22 / 38$ & 25 \\
5 & $\mathrm{LiCl} / \mathrm{ZnCl}_{2} / \mathrm{H}_{2} \mathrm{O}=32 / 27 / 41$ & 38 \\
6 & $\mathrm{Ca}(\mathrm{SCN})_{2} / \mathrm{ZnCl}_{2} / \mathrm{H}_{2} \mathrm{O}=25 / 37 / 38$ & 43 \\
\hline
\end{tabular}

Dissolving conditions: $80^{\circ} \mathrm{C}, 3$-h stirring.

roll (D) at $3 \mathrm{~m} / \mathrm{min}$ and then passed through a $0.5 \mathrm{wt} \%$ hydrochloric acid bath (E), washed with a washing roll $(\mathrm{F})$ and wound at a speed of $3 \mathrm{~m} / \mathrm{min}$. The wound-coagulated fiber $(\mathrm{G})$ was heat-dried using a 1-m hotplate (K) at $230^{\circ} \mathrm{C}$ with drawing rolls (I) and (J) both at a speed of $1 \mathrm{~m} / \mathrm{min}$. The undrawn fiber $(\mathrm{H})$ was heated on a $1 \mathrm{~m}$ hotplate $(\mathrm{K})$ at $240-270{ }^{\circ} \mathrm{C}$ while hot drawing it by varying the speed of either drawing roll (I) and (J). The drawn fiber was wound into a cheese-like package (L).

\section{RESULTS AND DISCUSSION}

\section{Properties of ECO Solutions Using Various Aqueous Metal Salt Solutions}

Table I shows the properties of ECO solutions obtained by adding $7.0 \mathrm{wt} \%$ ECO to aqueous metal salt solutions differing in composition. Three-hour stirring at $80^{\circ} \mathrm{C}$ dissolved the ECO and homogeneous ECO solution was obtained. However, clouding on lowering the temperature (phase separation temperature) was observed at $0{ }^{\circ} \mathrm{C}$ or above in solutions $4-6$. When these solutions were allowed to stand at lower temperature than the phase separation temperature, the solution lost fluidity and solidified into a gel.

Figure 3 shows phase separation temperatures versus polymer concentration curves for ECO solution with $\mathrm{CaCl}_{2} / \mathrm{ZnCl}_{2} / \mathrm{H}_{2} \mathrm{O}=40 / 22 / 38$ wt $\%$ solution. The solid line represents the boundary line at which phase separation occurs, above which a homogeneous solution is obtained and below which, a cloudy heterogeneous solution results. A higher polymer concentration in the solution produced a higher phase separation temperature. Clouding of the solution below the phase separation temperature is considered to reflect the non-uniformity of the polymer concentration and gel-like solidification of the solution is attributed to partial aggregation of ECO. Since the clouded solution returns to homogeneity if the temperature is increased above the phase separation temperature, cross-linking points in the gel are those of molecular entanglement and microcrystals.

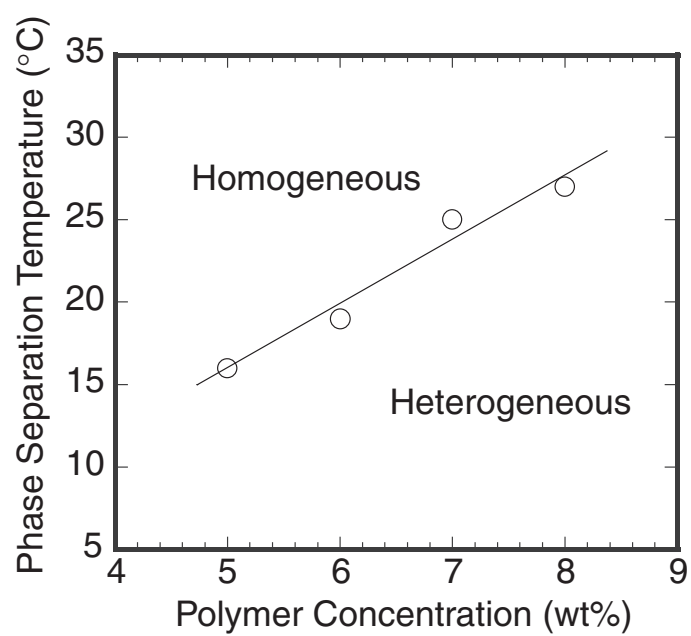

Figure 3. Phase separation temperature versus polymer concentration. Solvent: $\mathrm{CaCl}_{2} / \mathrm{ZnCl}_{2} / \mathrm{H}_{2} \mathrm{O}=40 / 22 / 38 \mathrm{wt} \%$ solution.

\section{Fiber Properties after Hot Drawing}

The authors investigated fiber properties after hot drawing, for wet spinning using two ECO solutions with and without a phase separation temperature. The solvent with a phase separation temperature was a $\mathrm{CaCl}_{2} / \mathrm{ZnCl}_{2} / \mathrm{H}_{2} \mathrm{O}=40 / 22 / 38$ wt $\%$ solution. A $\mathrm{ZnCl}_{2} / \mathrm{NaCl} / \mathrm{H}_{2} \mathrm{O}=65 / 10 / 25 \mathrm{wt} \%$ solution was used as a representative solvent without a phase separation temperature.

Figure 4 shows maximum tenacity after hot drawing versus coagulation temperature. The hot draw ratio for these measurements was approximately 17 . With the $\mathrm{CaCl}_{2} / \mathrm{ZnCl}_{2} / \mathrm{H}_{2} \mathrm{O}=40 / 22 / 38$ wt \% solution, tenacity greatly increased as coagulation temperature dropped below the phase separation temperature

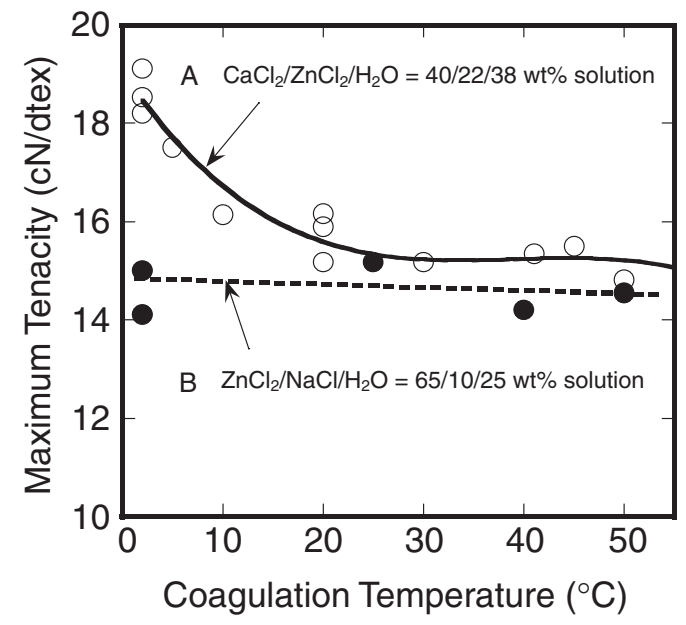

Figure 4. Maximum tenacity versus coagulation temperature. Line A: solvent: $\mathrm{CaCl}_{2} / \mathrm{ZnCl}_{2} / \mathrm{H}_{2} \mathrm{O}=40 / 22 / 38 \mathrm{wt} \%$ solution polymer concentration: $6.5 \mathrm{wt} \%$.

Line B: solvent: $\mathrm{ZnCl}_{2} / \mathrm{NaCl} / \mathrm{H}_{2} \mathrm{O}=65 / 10 / 25 \mathrm{wt} \%$ solution polymer concentration: $9 \mathrm{wt} \%$. 


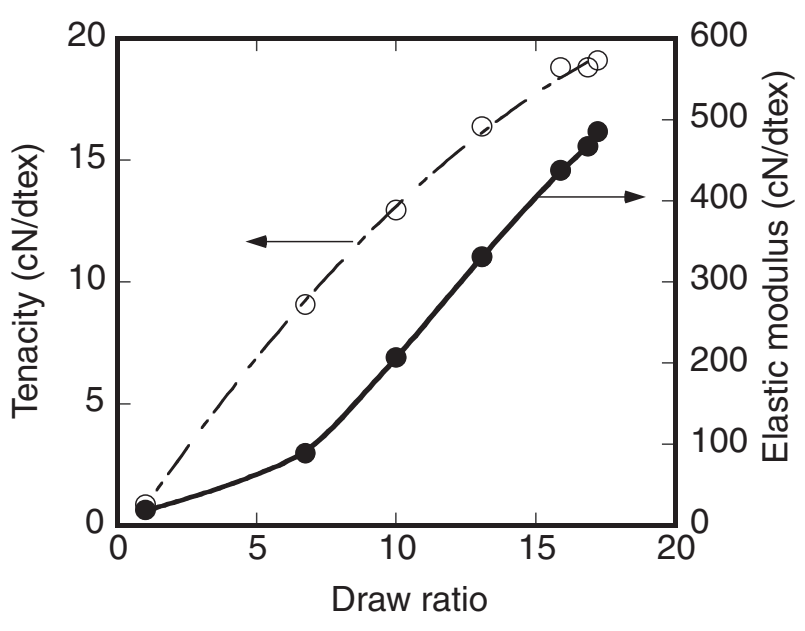

Figure 5. Changes in tenacity and elastic modulus of an ECO fiber with respect to draw ratio.

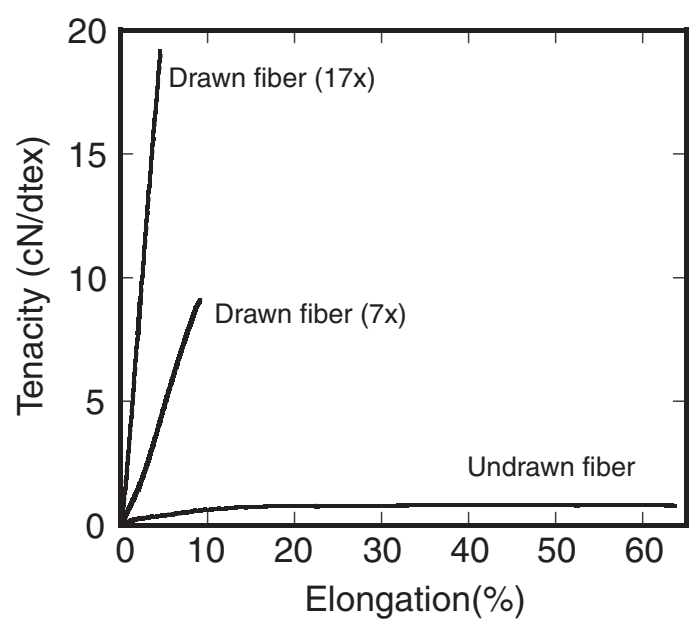

Figure 6. Stress-strain curve of ECO fibers with different draw ratios.

$\left(22^{\circ} \mathrm{C}\right)$. Figure 5 shows changes in tenacity and elastic modulus versus the draw ratio at a coagulation temperature of $2{ }^{\circ} \mathrm{C}$. Maximum tenacity was $19.0 \mathrm{cN} / \mathrm{dtex}$ $(2.5 \mathrm{GPa})$, and maximum elastic modulus, $480 \mathrm{cN} /$ dtex $(63 \mathrm{GPa})$. Figure 6 shows the stress-strain curve of the ECO fiber. This fiber had properties comparable to those of high performance fibers.

With the $\mathrm{ZnCl}_{2} / \mathrm{NaCl} / \mathrm{H}_{2} \mathrm{O}=65 / 10 / 25$ wt $\%$ solu- tion, tenacity was roughly constant at $15 \mathrm{cN} / \mathrm{dtex}$ $(1.9 \mathrm{GPa})$, even with change in coagulation temperature.

The polymer solution with the $\mathrm{CaCl}_{2} / \mathrm{ZnCl}_{2} / \mathrm{H}_{2} \mathrm{O}$ $=40 / 22 / 38 \mathrm{wt} \%$ solution gels throughout the entire filament interior on entering the coagulation bath below the phase separation temperature, to produce a homogeneous fiber structure. After gelling, the metal salt began to diffuse to the outside of the filament due to water penetration through the surface, but the gelled structure was maintained. A coagulated filament with a uniform structure suffers minimal may have during hot drawing and orientation of ECO molecules in the fiber axis direction may proceed in a uniform manner, resulting in an ECO fiber with high strength and elastic modulus.

With the $\mathrm{ZnCl}_{2} / \mathrm{NaCl} / \mathrm{H}_{2} \mathrm{O}=65 / 10 / 25$ wt \% solution, structural formation of the polymer solution in the coagulation bath proceeded due to penetration of the coagulant (water) from the fiber surface into the interior of the filament, causing differences in coagulating rate for the surface and interior, resulting in a non-uniform structure. The coagulated filament thus has a low tenacity even after hot drawing.

\section{REFERENCES}

1. B. J. Lommerts, E. A. Klop, and J. Aerts, J. Polym. Sci., Part B: Polym. Phys., 31, 1319 (1993).

2. H. G. Kormelink, M. Vlug, and J. E. Flood, Chem. Fibers Int., 49, May, 208 (1999).

3. P. Gupta, J. T. Schulte, J. E. Flood, and J. E. Spruifll, J. Appl. Polym. Sci., 82, 1794 (2001).

4. H. J. J. Rutten, E. P. Appl., 472, 630 (1990).

5. H. T. Maat, P. J. Cloos, H. v. D. Werff, and B. J. Lommerts, European Patent Appl., 647, 282 (1993).

6. A. Nobel, Chem. Fibers Int., 48, April, 88 (1998).

7. J. Kato, T. Morita, and K. Fujieda, PCT WO00/09611 (1999).

8. J. Kato, T. Morita, and R. Taniguchi, PCT WO02/068738 (2002).

9. J. A. M. v. Broekhoven and R. L. Wife, European Patent Appl., 257, 663 (1987).

10. J. A. M. v. Broekhoven and W. Miedema, European Patent Appl., 360, 359 (1989). 